\title{
Macrophage depletion suppresses sympathetic hyperinnervation following myocardial infarction
}

\author{
Gwenaelle Wernli, \\ Department of Molecular and Integrative Physiology, Kansas Intellectual and Developmental \\ Disabilities Research Center, University of Kansas Medical Center, Mail Stop 3051, 3901 \\ Rainbow Boulevard, Kansas City, KS 66160, USA
}

\section{Wohaib Hasan,}

Department of Molecular and Integrative Physiology, Kansas Intellectual and Developmental Disabilities Research Center, University of Kansas Medical Center, Mail Stop 3051, 3901

Rainbow Boulevard, Kansas City, KS 66160, USA

\section{Aritra Bhattacherjee, \\ Department of Molecular and Integrative Physiology, Kansas Intellectual and Developmental Disabilities Research Center, University of Kansas Medical Center, Mail Stop 3051, 3901 Rainbow Boulevard, Kansas City, KS 66160, USA}

Nico van Rooijen, and Department of Cell Biology and Immunology, Faculty of Medicine, Vrije Universiteit, Amsterdam, The Netherlands

\author{
Peter G. Smith \\ Department of Molecular and Integrative Physiology, Kansas Intellectual and Developmental \\ Disabilities Research Center, University of Kansas Medical Center, Mail Stop 3051, 3901 \\ Rainbow Boulevard, Kansas City, KS 66160, USA psmith@kumc.edu
}

\begin{abstract}
Myocardial infarction induces sympathetic axon sprouting adjacent to the necrotic region, and this has been implicated in the etiology of arrhythmias resulting in sudden cardiac death. Previous studies show that nerve growth factor (NGF) is essential for enhanced post-infarct sympathetic sprouting, but the cell types necessary to supply this neurotrophic protein are unknown. The objective of the present study was to determine whether macrophages, which are known to synthesize NGF, are necessary for post-infarct cardiac sympathetic sprouting. Ovariectomized female rats received left coronary artery ligation or sham operation, followed by intravenous injection of liposomes containing saline vehicle or clodronate, which kills macrophages. Shamoperated myocardium contained some sympathetic axons, few myofibroblasts and $\mathrm{T}$ cells and no CD-68-positive macrophages. In rats receiving saline liposomes through 7 days post-ligation, the posterolateral infarct border contained numerous myofibroblasts, macrophages and $\mathrm{T}$ cells, and sympathetic innervation was increased twofold. Treatment with clodronate liposomes reduced macrophage numbers by $69 \%$, while myofibroblast area was reduced by $23 \%$ and $\mathrm{T}$ cell number was unaffected. Clodronate liposome treatment reduced sympathetic axon density to levels comparable to the uninfarcted heart. NGF protein content measured in western blots was reduced to $33 \%$ of that present in infarcts where rats received saline-containing liposomes. Tissue morphometry confirmed that NGF immunostaining was dramatically reduced, and this was attributable primarily to reduced macrophage content. These results show that macrophage
\end{abstract}

(C) Springer-Verlag 2009

Correspondence to: Peter G. Smith. 
destruction markedly reduces post-infarction levels of NGF and that the presence of elevated numbers of macrophages is obligatory for development of sympathetic hyperinnervation following myocardial infarction.

\section{Keywords}

Myocardial infarction; Sympathetic hyperinnervation; Macrophages; Nerve growth factor; Inflammation

\section{Introduction}

Sudden cardiac death is a major clinical problem, accounting for more than 300,000 deaths annually in the United States [46]. The risk of sudden cardiac death is especially high after myocardial infarction (MI) as 75\% of victims have had a previous MI [45], generally within 30 days of death [55]. The direct cause of sudden cardiac death is most often ventricular tachycardia leading to ventricular fibrillation [6]. Although the etiology of these post-MI ventricular arrhythmias remains incompletely understood, an increase in sympathetic nerve density at the infarct border zone has been implicated [7]. We and others have shown that sympathetic hyperinnervation peaks 7 days after occlusion of the left coronary artery and decreases gradually through 28 days post-MI in rodents and dogs $[26,65]$ and this time course is consistent with the highest risk of sudden cardiac death observed clinically in humans [55].

Several lines of evidence suggest that nerve growth factor (NGF), a potent sympathetic neurotrophic protein [34], may play a role in post-MI sympathetic sprouting [9, 65]. In explant cultures of infarcted tissue, NGF antibody neutralization blocked neurite outgrowth from sympathetic ganglia, demonstrating that NGF is required for development of sprouting at the infarct border zone [26]. Similarly, in vivo studies where synthetic glucocorticoids were administered following MI showed reductions in infarct border zone sympathetic hyperinnervation [14], and it is well established that these hormones generally suppress NGF production [37]. Accordingly, NGF synthesis within the infarcted region is likely to play a causal role in inducing local sympathetic sprouting.

Despite evidence that NGF synthesis is required for sympathetic hyperinnervation, the cellular mechanisms leading to elevated NGF synthesis following MI remain unclear. In the normal rat heart, sympathetic innervation density correlates with NGF mRNA levels [52] suggesting that NGF upregulation in cardiac myocytes after injury could be a contributing factor. However, the border zone between damaged and intact myocardium also contains increased numbers of macrophages and myofibroblasts [26]. Wounds such as those created by ischemic injury are characterized by an influx of macrophages deriving from vascular monocytes that assist healing by phagocytosing cellular debris and secreting a variety of cytokines and growth factors. Cytokines present in inflammatory environments are known to promote activation of macrophages [1] and in vitro macrophage activation induces NGF expression [8], suggesting that macrophages could contribute to sympathetic hyperinnervation. Myofibroblasts are thought to transdifferentiate from fibroblasts, pericytes, and possibly macrophages [27, 50], and to promote wound healing through contraction and collagen deposition. Myofibroblasts, as well as another inflammatory wound cell, the T cell, are also known to synthesize NGF [26], making them possible contributors to the induction of sympathetic hyperinnervation.

In the present study, we assessed the role of macrophages in the development of post-MI sympathetic hyperinnervation. We administered clodronate-containing liposomes, which are 
phagocytosed by macrophages and cause selective macrophage apoptosis and depletion [62]. Our findings show that reductions in the macrophage population dramatically reduce sympathetic hyperinnervation and NGF content following experimental MI.

\section{Materials and methods}

\section{Experimental preparations}

All experimental protocols conformed to NIH guidelines and were approved by the University of Kansas Medical Center Animal Care and Use Committee. Thirty-three female Sprague-Dawley rats (60 days old, $200 \mathrm{~g}$, Harlan Breeding Laboratories) were anesthetized by intraperitoneal injection of $60 \mathrm{mg} / \mathrm{kg}$ ketamine, $8 \mathrm{mg} / \mathrm{kg}$ xylazine, and $0.4 \mathrm{mg} / \mathrm{kg}$ atropine. To minimize the influence of reproductive hormones and also to simulate postmenopausal conditions that are associated with reduced cardioprotective effects [24, 30], ovaries were removed by flank incisions [67]. Seven days after ovariectomy, rats were anesthetized as above, respired mechanically, and the left anterior descending coronary artery was ligated with silk suture as described previously [26, 51]. In sham surgeries, a suture was passed around the artery but left untied. Following coronary artery ligation (CAL) or sham ligation, rats received tail vein injections on days 1, 3, and 5 of liposomes containing clodronate [48] or phosphate-buffered saline, or normal saline (1 ml/100 g body weight). Clodronate was a gift from Roche Diagnostics GmbH, Mannheim, Germany [61].

Seven days after CAL, rats were reanesthetized as above and hearts were harvested. The efficacy of the ligation in producing ventricular infarction was confirmed in preliminary observations by immersion in $1 \%$ triphenyl tetrazolium chloride (TTC) in phosphate buffer for $30 \mathrm{~min}$ at $40^{\circ} \mathrm{C}$ followed by fixation in formal saline [36]. Other hearts were harvested, embedded in tissue freezing medium (Triangle Biomedical Sciences, Durham, NC, USA) and snap frozen in isopentane cooled in liquid nitrogen and stored at $-80^{\circ} \mathrm{C}$.

\section{Infarct assessment}

Because of anatomical variation in coronary arterial vasculature, ischemic damage was variable and was more limited in some hearts than in others. To ensure that analyses were conducted on specimens with comparable damage in all groups, infarcts that did not span the entire thickness of ventricular wall or only partially affected the left ventricle were excluded from further study. The numbers of infarctions excluded in each group was 2 of $7(28 \%)$ in the saline liposome group, 1 of $7(14 \%)$ in the saline-injected group, and 4 of $11(36 \%)$ in the clodronate liposome treatment group.

Hearts were cryosectioned serially at $10 \mathrm{~lm}$ thickness perpendicular to the apical-basal axis. To establish the physical dimensions of infarcts, one set of six sections taken at $1.7 \mathrm{~mm}$ intervals through the entire ventricle was stained with Masson's Trichrome according to a standard protocol (Diagnostic BioSystems, Pleasanton, CA, USA). Sections were fixed for $10 \mathrm{~min}$ in $4 \%$ paraformaldehyde and $20 \mathrm{~min}$ at $50^{\circ} \mathrm{C}$ in Bouin's solution (Electron Microscopy Sciences, Hatfield, PA, USA). Images of infarcts were captured using a Nikon SMZ 1500 microscope with a $1 \times$ objective at 0.75 optical zoom. The area of the infarction and of the left ventricle were measured (AnalySis, Soft Imaging System, Lakewood, CO, USA), and the percentage of infarcted area of the left ventricle was calculated on each section and was expressed as a mean of the six sections for each heart.

\section{Sympathetic innervation}

To assess sympathetic innervation density, we analyzed four sections adjacent to the Masson's trichrome-stained set; the first section for analysis was taken $1.5-2 \mathrm{~mm}$ apical to the ligation, which ensured that we did not include tissue with local inflammation due to the 
ligation. Sections were fixed at $4^{\circ} \mathrm{C}$ in methanol, blocked with normal goat serum, and immunostained overnight for the selective sympathetic axon marker dopamine $\beta$ -

hydroxylase (DBH, 1:600, rabbit IgG, Immunostar, Hudson, WI, USA), followed by a $2 \mathrm{~h}$ incubation in goat anti-rabbit IgG conjugated to Alexa 555 (1:500, Invitrogen, Carlsbad, CA, USA). For each section, six fields evenly distributed within the left lateral posterior aspect of the infarct were captured with a 40x objective using a Nikon Eclipse TE300 (indicated by boxes in Fig. 1a-c); preliminary observations showed sympathetic innervation associated with the infarcted tissue was preferentially distributed within this region. In sham hearts, images were taken in an identical fashion from comparable areas. Nerve density was calculated by superimposing a stereological grid $(8 \mu \mathrm{m}$ line interval) over the captured image, counting grid intersections over nerves and dividing by the total number of intersections over the sampled tissue [66, 67]. Vascular innervation was excluded from quantification. To confirm that the changes observed with the quantification of DBH were not caused by changes of the level of that enzyme alone, adjacent sections to the ones stained for DBH were fixed in $4 \%$ paraformaldehyde for $5 \mathrm{~min}$, blocked with normal goat serum, and immunostained overnight for the intermediate filament marker peripherin (1:1,000, chicken IgG, Chemicon, Temecula, CA, USA) followed by a $2 \mathrm{~h}$ incubation with goat anti-chicken IgG conjugated to cy2 (1:200, GeneTex, San Antonio, TX, USA). Another set of adjacent sections was fixed in $4 \%$ paraformaldehyde for $5 \mathrm{~min}$, blocked with normal goat serum, and immunostained overnight for the selective axon marker tyrosine hydroxylase (TH, 1:300, rabbit IgG, Chemicon) followed by a $2 \mathrm{~h}$ incubation in goat antirabbit IgG conjugated to cy3 (1:400, Jackson, West Grove, PA, USA).

\section{Inflammatory cells}

A second set of sections adjacent to the DBH-immunostained series was stained for CD68 (1:200, mouse monoclonal, MAB 1435, Chemicon), a marker for tissue macrophages and blood monocytes [40]. A third set was stained for a-smooth muscle actin (1/200, mouse monoclonal 1A4, Sigma, St Louis, MO, USA), which identifies myofibroblasts [27, 53]. A fourth set of adjacent sections was immunostained for the T cell antigen receptor TCR $\alpha / \beta$ (1:100, mouse monoclonal, clone R73, Serotec, Oxford, UK). All inflammatory cell markers were co-stained with rabbit IgG recognizing rat NGF (1:100, M-20, Santa Cruz, Santa Cruz, CA, USA). Secondary antibodies were Alexa 488-conjugated goat anti-mouse (1:1,000 Invitrogen) and Alexa 555-conjugated goat anti-rabbit (1:500 Invitrogen). Antibody specificities were confirmed using antigen preadsorbtion with a 10-fold excess of the peptide and primary antibody omissions.

Macrophage, myofibroblasts, and $\mathrm{T}$ cells were quantified by capturing four images with a $40 \times$ objective on a Nikon Eclipse C1 Si confocal microscope from each stained section in the same areas as those used for innervation assessment. To quantify macrophages, numbers of CD68-immunoreactive (ir) cells per field were counted and expressed as the average number of cells per $\mathrm{mm}^{2}$ (Metamorph, Molecular Devices, Downingtown, PA, USA). In addition, average macrophage size was estimated by measuring total section area occupied by CD68-ir by threshold detection and dividing it by the total number of CD68-ir macrophages. Because myofibroblasts form sheet-like aggregates within the infarct, counting individual cells is not feasible. Therefore, myofibroblasts were quantified by measuring the area per field occupied by a-SMA-ir cells, taking care to exclude a-SMA-ir vascular smooth muscle; the percentage of field area was assessed by counting stereological grid intersections overlying myofibroblasts, dividing this by total number of intersects within that field, and expressing this as area per $\mathrm{mm}^{2}$ (AnalySis, Soft Imaging System). $\mathrm{T}$ cells associated with the infarct were assessed by counting TCR $\alpha / \beta$-ir cells per each of the four fields and expressed as the average numbers of cells per $\mathrm{mm}^{2}$. 


\section{NGF and cytokine content}

The content of NGF protein in infarct tissue was quantified by western blots. Infarcted hearts from three saline liposome and four clodronate liposome rats were snap frozen and the border region with adjacent intact myocardium was dissected out and homogenized in Ripa buffer (50 mM Tris- $\mathrm{HCl} \mathrm{pH} 7.4,150 \mathrm{mM} \mathrm{NaCl}, 1 \% \mathrm{NP}-40,0.25 \%$ sodium deoxycholate, $1 \mathrm{mM}$ EDTA) with $10 \%$ protease inhibitor (Sigma) and 1\% phosphatase inhibitor (Sigma). Fifty micrograms of protein was loaded on a gel and western blot was performed according to protocol (Invitrogen). The membrane was stained overnight with rabbit anti-NGF (1:500, Santa Cruz) in 5\% goat serum and $2 \mathrm{~h}$ in goat anti-rabbit HRP (1:5,000, Sigma). After revealing the bands with SuperSignal West Pico Stable Peroxide Solution (Thermo Sc., Rockford, IL, USA), their intensities were analyzed using a Chemi Doc XRS and quantification was performed using Quantity One software (BioRad, Hercules, CA, USA). Total protein stained with India ink was used to verify that equal amount of proteins were loaded on the gel and transferred to the membrane. The total density assessed by India ink was constant between samples and was used to normalize the density of the NGF bands.

The contribution of each cell type to the NGF content within the infarct was assessed in samples co-stained for the cell-selective markers and for NGF. For both CD68-ir and TCRa/ $\beta$-ir cells, numbers of cells co-expressing both proteins were counted in each of the four sample regions and normalized to $1 \mathrm{~mm}^{2}$. In addition, for both markers the total field area occupied by NGF-ir/CD68-ir macrophages and NGF-ir/TCRa/ $\beta$-ir T cells was measured by threshold detection (Metamorph, Molecular Devices) and the average area for the four fields expressed as $\mu \mathrm{m}^{2} / \mathrm{mm}^{2}$. The contribution of myofibroblasts to NGF expression within the infarct was assessed by superimposing a stereological grid $(30 \mu \mathrm{m}$ line interval, AnalySis, Soft Imaging System) over captured images and counting intersections overlying regions of NGF/a-SMA-ir colocalization (i.e. yellow in merged images), dividing by the total number of sample area intersections, and normalizing to $1 \mathrm{~mm}^{2}$.

The effect of clodronate liposomes on the infarct content of mRNA encoding the inflammatory cytokines interferon- $\gamma(\mathrm{IFN}-\gamma)$, tumor necrosis factor-a (TNF-a) and macrophage chemotactic protein-1 (MCP-1) was evaluated in the samples obtained from the same specimens used for NGF western blot analysis. Dissected regions were homogenized in ice cold trizol and total RNA $(1 \mu \mathrm{g})$ reverse transcribed using the iScript kit (Biorad). Amplification of cDNA was conducted using specific primers for IFN- $\gamma$, TNF-a, MCP-1 and GAPDH. Conditions for the PCR were $94^{\circ} \mathrm{C}$ for $40 \mathrm{~s}, 60^{\circ} \mathrm{C}, 57^{\circ} \mathrm{C}, 53.7^{\circ} \mathrm{C}$, and $60^{\circ} \mathrm{C}$ for $30 \mathrm{~s}$, and $72^{\circ} \mathrm{C}$ for $1 \mathrm{~min}$ for $30,32,31$, and 28 cycles, respectively, for IFN- $\gamma$, TNF-a, $\mathrm{MCP}-1$, and GAPDH, with a final extension at $72^{\circ} \mathrm{C}$ for $5 \mathrm{~min}$. The primers were $5^{\prime}$ ATGGATGCTATGGAAGGAAAG-3' (sense) and $5^{\prime}$-TATTGGCACACTCTCTACCC- ${ }^{\prime}$ (antisense) for IFN- $\gamma, 5^{\prime}$-CTTATCTACTCCCAGGTTCTC-3' (sense) and $5^{\prime}$ -

ACTTCAGCATCTCGTGTG-3' (antisense) for TNF- $a ; 5^{\prime}-$

ACTCATTCACTGGCAAGATG-3' (sense) and $5^{\prime}$-GGTCAAGTTCACATTCAAAGG-3' (antisense) for MCP-1; 5' -CTCTACCCACGGCAAGTTC-3' (sense), and 5' -

CTCAGCACCAGCATCACC- $3^{\prime}$ (antisense) for GAPDH. Five microliters of PCR product was analyzed by electrophoresis (1.5\% agarose gel with ethidium bromide). Bands were visualized under UV transillumination using a Chemi Doc XRS and quantified as above.

\section{Statistics}

Data are expressed as mean \pm SEM. Data were analyzed using one-way ANOVA followed by a Student-Newman-Keuls test or Student $t$ test (SigmaStat 3.11, Systat Software, Inc., San Jose, CA, USA). Statistical significance was accepted at $P \leq 0.05$. No statistically significant differences were evident in any of the measurements obtained from groups 
receiving CAL followed by saline or by saline-containing liposomes, and these groups were therefore pooled into a single 'saline' group for subsequent analyses.

\section{Results \\ Infarct characterization}

No post-operative deaths occurred in the sham-ligated subjects ( $N=4$ in each sham group), while mortality was $21 \%(3 / 14)$ in the group receiving CAL plus saline and $27 \%(3 / 11)$ in the group receiving CAL plus clodronate liposomes. Characterization of the infarct by TTC and light microscopic analysis showed that left CAL consistently produced an extensive area of necrosis that was confined to the left ventricle with minimal septal or right ventricular involvement (Fig. 1). Following exclusion of hearts that did not meet the transmural and size criteria, infarcts occupied $38.7 \pm 4.5 \%$ of the left ventricle in the saline CAL group and 42.3 $\pm 10.1 \%$ of the left ventricle in the clodronate liposome CAL group.

\section{Innervation and inflammatory cell composition of uninjured hearts}

Ventricular tissue from rats receiving a sham ligation displayed morphological features similar to those we have reported previously for control animals [26]. DBH-ir nerves were sparse (Fig. 2a) and present mainly in association with ventricular cardiomyocytes. Quantitative analysis showed that DBH-ir sympathetic innervation occurred with a density of $0.84 \pm 0.07 \%$ throughout the six ventricular sample regions. In rats with a sham ligation, treatment with clodronate liposomes had no effect on DBH-ir sympathetic innervation density relative to saline controls (Fig. 2a, d).

In sections apical to the untied ligature, essentially no CD68-ir macrophages were observed (Fig. 2e, h). We occasionally encountered a-SMA-ir cells resembling myofibroblasts but their incidence was low (Fig. 2i, 1). Similarly, TCR $\alpha / \beta$-ir T cells were encountered infrequently (Fig. 2m, p).

\section{Effect of infarction on innervation and inflammatory cell composition}

Seven days following CAL, DBH-ir sympathetic axon density at the border region of the infarct was increased twofold relative to that of control ventricular tissue (Fig. 2b, d). Consistent with previous findings [26], this was associated with a dramatic increase in macrophage density to about 1,200 cells $/ \mathrm{mm}^{2}$ (Fig. 2f, h). Area occupied by a-SMA-ir myofibroblasts area was increased approximately 40 -fold to about $130,000 \mu \mathrm{m}^{2} / \mathrm{mm}^{2}$ (Fig. $2 \mathrm{j}, \mathrm{l}$ ). T cells also increased from negligible numbers in controls to about 39 cells $/ \mathrm{mm}^{2}$ (Fig. $2 n, p)$.

\section{Effect of clodronate liposomes on innervation and inflammatory cell composition following CAL}

In rats receiving CAL followed by intravenous injections of clodronate liposomes, $\mathrm{DBH}$-ir sympathetic innervation density was reduced by $66 \%$ relative to untreated CAL ventricles, and was comparable to that of unligated ventricles (Fig. 2c, d). To confirm that this reduction was not simply due to DBH depletion within structurally intact sympathetic axons, we immunostained adjacent sections for the intermediate filament protein peripherin, which labels all intact unmyelinated axons, and TH as an alternative noradrenergic marker.

Staining patterns for DBH-ir axons in saline-injected rats with CAL were comparable to those of TH and peripherin (Fig. 3a-c). Similarly, the reduction in numbers of DBH-ir fibers in rats with CAL and clodronate liposome treatment was comparable to that observed for TH and peripherin (Fig. 3d-f). 
Clodronate liposome treatment also reduced numbers of macrophages by $69 \%$ (Fig. $2 \mathrm{~g}, \mathrm{~h}$ ) and macrophage size by $21 \%\left(41.5 \pm 2.2 \mu \mathrm{m}^{2}\right.$ with saline treatment and $32.7 \pm 2.3 \mu \mathrm{m}^{2}$ with clodronate treatment, $P=0.015$ ), although they remained significantly more abundant than in control ventricles. Consistent with previous findings, macrophage depletion was associated with reduced IFN- $\gamma$ gene expression (Fig. 4a) in the infarct [49, 59], while TNF$a$ and MCP-1 were unchanged [38, 58] (Fig. 4b, c).

The wound area occupied by myofibroblasts was also significantly reduced by $22 \%$ relative to untreated CAL tissue but remained elevated relative to unligated ventricles (Fig. 2k, 1). T cell numbers were not affected by clodronate liposome treatment (Fig. 2o, p).

\section{Effect of clodronate liposomes on infarct NGF expression}

Previous studies have implicated NGF in post-infarct sympathetic sprouting $[9,65]$ and we have shown in culture that NGF neutralization eliminates sprouting induced by the infarcted myocardium [26]. Accordingly, we assessed the extent to which clodronate liposome treatment altered infarct NGF.

In the infarct border region of saline-treated rats, mature NGF protein was $3.34 \times 10^{-3}$ INT $\times$ $\mathrm{mm}^{2}$. After treatment with clodronate liposomes, NGF was reduced by $67 \%$ to $1.10 \times 10^{-3}$ INT $\times \mathrm{mm}^{2}$ (Fig. 5).

To determine the contribution of the predominant NGF-expressing cell types in the vicinity of the infarct $[8,26,27,43]$, we analyzed the NGF expression of macrophages, myofibroblasts and $\mathrm{T}$ cells. In ventricles with sham ligations, no macrophages were observed below the untied ligature and therefore did not contribute to NGF expression in the control ventricle (Fig. 6a-c). Following CAL, all CD68-ir macrophages expressed NGF-ir (Fig. 6d-g). After clodronate liposome treatment, CD68-ir macrophages that remained continued to express NGF-ir at intensities comparable to untreated CAL (Fig. 6d, i-k). To assess how macrophage depletion affected NGF tissue content, we computed section area occupied by NGF-ir macrophages. While macrophages did not contribute to NGF-ir in control tissues, section area occupied by NGF-ir macrophages was $~ 50,000 \mu \mathrm{m}^{2} / \mathrm{mm}^{2}$ in the saline CAL group, and this was reduced to $\sim 13,000 \mu \mathrm{m}^{2} / \mathrm{mm}^{2}$ by clodronate liposome treatment (Fig. 6h).

In ventricles of rats with sham ligations, NGF-ir was observed in only $17 \pm 3 \%$ of myofibroblast a-SMA-ir cytoplasmic area (Fig. 7a-d) and this was unchanged by clodronate liposome injections (Fig. 7d). Section area occupied by NGF-ir and aSMA-ir colocalization was about $1,300 \mu \mathrm{m}^{2} / \mathrm{mm}^{2}$. Due to the limited numbers of myofibroblasts, the contribution of myofibroblasts to NGF expression in sham-ligated ventricles was negligible (Fig. 7h). Following CAL, the percentage of a-SMA-ir cytoplasm occupied by NGF-ir increased to 37 $\pm 2 \%$ (Fig. 7d-g), and total NGF-ir+aSMA-ir area increased 97-fold (Fig. 7h). Clodronate liposome treatment did not alter the percentage of a-SMA-ir cytoplasm with NGF-ir (Fig. $7 \mathrm{~d}, \mathrm{i}-\mathrm{k}$ ), but the total area occupied by these colocalized markers decreased in concert with the reduction in myofibroblast content (Fig. 7h).

In ventricles with sham ligations, $8 \pm 8 \%$ of TCR $a / \beta$-ir T cells showed NGF-ir (Fig. $8 \mathrm{a}-\mathrm{d}$ ), and these occupied $32 \pm 19 \mu \mathrm{m}^{2} / \mathrm{mm}^{2}$ (Fig. $8 \mathrm{~h}$ ). In ventricles of sham-ligated rats receiving clodronate liposomes, the percentage of T cells with NGF-ir was greater than in salineinjected controls (Fig. 8d) and area occupied was $517 \pm 207 \mu \mathrm{m}^{2} / \mathrm{mm}^{2}$ (Fig. 8h). CAL increased the percentage of T cells expressing NGF and their area relative to saline-injected sham controls (Fig. 8d-h). In addition, in CAL rats receiving clodronate liposomes, the number of TCR $\alpha / \beta$-ir T cells expressing NGF-ir was increased, as was the area occupied by NGF-ir within these cells (Fig. 8h-k). 


\section{Discussion}

Prolonged myocardial ischemia leads to extensive cardiomyocyte necrosis, which results in both a reduction in cardiac performance and a thinning of the myocardial wall. Accordingly, it is important that cellular debris be removed and tissue repair initiated quickly in order to maintain cardiovascular homeostasis. In association with this damage, locally produced chemokines and cytokines initiate an inflammatory response that attract and activate circulating macrophages. These cells perform an important role in removing debris left by the necrotic cells [16]. Additionally, they are essential for tissue repair [15, 19, 41, 64]. Growth factors released by these cells promote proliferation of endothelial cells, fibroblasts and myofibroblasts, which are important in revascularization, forming extracellular matrices, and providing tensile strength to the scar. Proinflammatory cytokines are present in experimental models of MI [12, 17, 18] and are produced by many cells types [2, 10, 20, $23,57]$. These cytokines, activate macrophages [25] and promote $\mathrm{T}$ cell activation and proliferation [42]. NGF also plays important roles in differentiation and proliferation of inflammatory cells $[4,39,42]$. In addition to its role in inflammatory cell differentiation, NGF is known to promote aggressive sprouting of sympathetic nerves. By activating the trkA receptor present on sympathetic axons, NGF promotes regeneration and outgrowth. Hence, NGF is important in both the inflammatory response and in the remodeling of innervation following infarction.

Previous studies have shown that, within the cardiac ischemic wound, multiple cell types can synthesize NGF. Both NGF mRNA and protein have been detected in post-infarction macrophages and myofibroblasts, in T cells and in surviving cardiac ventricular myocytes as well as vascular smooth muscle $[14,26,65]$. Therefore, multiple cell types may contribute to local NGF production. The extent to which these various cell types contribute to sympathetic axon remodeling after infarction is not clear. In the present study, we focused on the role of macrophages. Macrophages have been implicated in neuronal sprouting after wounds in the central nervous system [5]. In addition to synthesizing NGF, macrophages release a variety of other factors that may be important in orchestrating recruitment, proliferation and differentiation of other wound cell types.

To selectively deplete macrophages, we used liposomes containing clodronate [61]. Clodronate liposomes do not cross blood vessel walls but are phagocytosed by circulating monocytes where the accumulated clodronate leads to irreversible toxicity and apoptosis [62]. Sustained treatment is reported to effectively reduce tissue macrophage populations $[22,48]$, and our regimen reduced CD68-ir macrophages by $69 \%$ in infarcted hearts, comparable to that reported previously [60]. In addition, we observed that the size of surviving macrophages was modestly reduced. Consistent with this reduction, mRNA encoding IFN- $\gamma$, which is expressed mainly by macrophages, T cells and NK cells [20, 23, $44]$ was reduced by $31 \%$, and this reduction is consistent with findings by others [49, 59]. However, some other cytokines did not show significant changes. Neither TNF-a, a cytokine secreted by multiple cell types including macrophages, neutrophils, mast cells, and cardiomyocytes $[17,29]$ nor MCP-1, which is expressed by macrophages, endothelial cells, fibroblasts, neutrophils, and cardiomyocytes [47], were significantly decreased by clodronate liposomes. While it is unclear how cytokine content is maintained in the face of macrophage depletion, our findings are consistent with others where these proteins were found to be unchanged $[38,58]$. These observations suggest that the ability of clodronate liposomes to prevent sympathetic hyperinnervation is probably not due to a generalized suppression of inflammatory proteins within the infarcted tissue.

While clodronate liposome treatment depleted wound macrophages, effects on other cells were limited. Clodronate liposome treatment did not affect $\mathrm{T}$ cell numbers, although it did 
cause a modest reduction in wound area occupied by aSMA-ir myofibroblasts. This effect appears to be confined to the wound myofibroblasts, as treatment did not alter the small numbers of myofibroblasts present in non-infarcted hearts. Clodronate liposomes are known to be highly selective for phagocytic macrophages [61], so it seems unlikely that this is a direct effect on myofibroblasts, which are not known to be phagocytic. Rather, it is likely to have occurred secondary to the depletion in macrophages. Myofibroblasts transdifferentiate from several cell types including fibroblasts and pericytes [21, 27, 50]. Development of the myofibroblast phenotype requires the presence of various secreted proteins including TGF- $\beta$ $[11,13]$, which can be released by macrophages [3]. In addition, macrophages can express aSMA [27] and may themselves be precursors to myofibroblasts. Depletion of macrophages by clodronate liposomes may thus account for some of the reduction of aSMA-ir myofibroblasts as well. Accordingly, clodronate-induced depletion appears to have a small but significant effect in reducing myofibroblast contributions to the ischemic wound as a result of an altered wound milieu, reduced precursor cell numbers, or both.

Clodronate treatment produced a marked reduction in the numbers of sympathetic nerves in the vicinity of the infarct. Sympathetic hyperinnervation is well documented in the infarct border zone [26, 63]. While sympathetic nerves may play a role in tissue remodeling after injury $[31,54,56]$, a link between sympathetic hyperinnervation and post-infarct arrhythmias is believed to underlie sudden cardiac death [7]. While the present study provides strong evidence that sympathetic hyperinnervation requires increased numbers of macrophages, additional studies with larger numbers of rats and a more protracted time course will be required to assess any impact of clodronate liposome treatment on post-infarct survival. Similarly, the extent to which other factors reported to modulate infarct sympathetic hyperinnervation, which include estrogen [33], statin treatment [32], and glucocorticoids [14], affect macrophage dynamics and NGF expression remain to be elucidated.

The present findings show that, in the absence of normal numbers of macrophages, sympathetic hyperinnervation fails to develop at the site of the ischemic injury. This is not likely to be due to an effect of clodronate liposomes on sympathetic innervation as sympathetic nerve density was unaffected in sham-ligation subjects. Because clodronate liposomes directly affect macrophage numbers, this represents a probable cause for the reduced numbers of sympathetic nerves. Moreover, macrophages are robust sources of NGF, and this neurotrophin is required for post-infarct sympathetic sprouting [26]. However, macrophages secrete other factors that may modulate phenotype of other cell types within the wound, including their NGF expression. For example, treatments with clodronate liposomes were found to reduce cytokines produced by macrophages such as IFN $-\gamma[49$, 59], which may indirectly reduce sympathetic outgrowth by modulating NGF but is not known to directly elicit sympathetic sprouting. Accordingly, we assessed changes in NGF expression.

Clodronate liposome treatment decreased the expression of NGF by $67 \%$ in the border region when compared with saline liposome treatment suggesting that the decrease of this neurotrophin could account for the suppression of sympathetic hyperinnervation following clodronate liposome treatment. To determine the contribution of the different inflammatory cell types to this decrease, we analyzed the cellular distribution of NGF.

In sham-operated hearts, NGF-ir was present at low levels in cardiomyocytes and in a few CD68-ir myofibroblasts and TCR a/ $\beta$-ir T cells. Following infarction, there was a marked increase in NGF-ir in the infarct border region, and most was colocalized with CD68-ir macrophages and aSMA-ir myofibroblasts; TCR $\alpha / \beta$-ir T cells showed intense NGF 
immunofluorescence but were relatively few in number so that their contribution to overall NGF expression was quite small ( $1 \%$ of the tissue area showing NGF-ir).

Clodronate liposome treatment elicited a marked reduction in overall NGF immunostaining in the infarcted tissue. Coincident with the reductions in macrophage numbers (and to a lesser extent size), the total area occupied by colocalized CD68 and NGF immunofluorescence was reduced some $76 \%$ relative to saline treatment. Due to the reduction of aSMA-ir myofibroblast area, NGF expression by this cell population was also reduced after clodronate liposome treatment. Although aSMA-ir myofibroblast area showed a modest reduction after clodronate liposome treatment, the reduction in NGF content appeared to be more marked, suggesting that the reduction in macrophages may have also suppressed NGF expression in the myofibroblasts. Interestingly, while NGF immunoreactivity presented by both macrophages and myofibroblasts was reduced, expression by $\mathrm{T}$ cells was increased, now accounting for about $10 \%$ of NGF-ir cellular area. Overall, however, macrophage depletion by clodronate liposomes substantially reduced NGF in the region of the wound.

While some regions of the post-infarct heart show hyperinnervation, other ventricular regions have a pronounced loss of sympathetic nerves [35], suggesting that the wound environment contains both attractive and repulsive factors for sympathetic axons, which could account for the inhomogeneity of sympathetic innervation throughout the infarct. Indeed, while NGF within the infarct was reduced markedly by macrophage depletion, it remained at detectable levels but hyperinnervation was prevented. It is known that cardiac tissue expresses Sema3A, which acts to suppress cardiac innervation [28]. It may therefore be the case that the abundance of NGF in the infarct region induces sympathetic sprouting by overcoming repulsive effects of semaphorins or other unidentified proteins. Future studies aimed at determining how various attractive and repulsive factors interact to regulate cardiac innervation after injury may provide valuable insight into new strategies aimed at preventing abnormal cardiac excitability.

\section{Acknowledgments}

Supported by NIH HL079652, RR016475, and P30HD02528. Clodronate was a gift of Roche Diagnostics GmbH, Mannheim, Germany. We thank Dr. Donald Warn of the Kansas Intellectual and Developmental Disabilities Research Center Integrative Imaging Core for his assistance with imaging, Zhaohui Liao, Argenia Doss and Sarah Tague for their assistance with the animal preparations.

\section{References}

1. Adams DO, Hamilton TA. The cell biology of macrophage activation. Annu Rev Immunol. 1984; 2:283-318. [PubMed: 6100475]

2. Akasaka Y, Morimoto N, Ishikawa Y, Fujita K, Ito K, Kimura-Matsumoto M, Ishiguro S, Morita H, Kobayashi Y, Ishii T. Myocardial apoptosis associated with the expression of proinflammatory cytokines during the course of myocardial infarction. Mod Pathol. 2006; 19:588-598. [PubMed: 16554734]

3. Assoian RK, Fleurdelys BE, Stevenson HC, Miller PJ, Madtes DK, Raines EW, Ross R, Sporn MB. Expression and secretion of type beta transforming growth factor by activated human macrophages. Proc Natl Acad Sci USA. 1987; 84:6020-6024. [PubMed: 2888109]

4. Barouch R, Kazimirsky G, Appel E, Brodie C. Nerve growth factor regulates TNF-alpha production in mouse macrophages via MAP kinase activation. J Leukoc Biol. 2001; 69:1019-1026. [PubMed: 11404390]

5. Batchelor PE, Porritt MJ, Martinello P, Parish CL, Liberatore GT, Donnan GA, Howells DW. Macrophages and microglia produce local trophic gradients that stimulate axonal sprouting toward but not beyond the wound edge. Mol Cell Neurosci. 2002; 21:436-453. [PubMed: 12498785] 
6. Cao JM, Chen LS, KenKnight BH, Ohara T, Lee MH, Tsai J, Lai WW, Karagueuzian HS, Wolf PL, Fishbein MC, Chen PS. Nerve sprouting and sudden cardiac death. Circ Res. 2000; 86:816-821. [PubMed: 10764417]

7. Cao JM, Fishbein MC, Han JB, Lai WW, Lai AC, Wu TJ, Czer L, Wolf PL, Denton TA, Shintaku IP, Chen PS, Chen LS. Relationship between regional cardiac hyperinnervation and ventricular arrhythmia. Circulation. 2000; 101:1960-1969. [PubMed: 10779463]

8. Caroleo MC, Costa N, Bracci-Laudiero L, Aloe L. Human monocyte/macrophages activate by exposure to LPS overexpress NGF and NGF receptors. J Neuroimmunol. 2001; 113:193-201. [PubMed: 11164902]

9. Chen LS, Zhou S, Fishbein MC, Chen PS. New perspectives on the role of autonomic nervous system in the genesis of arrhythmias. J Cardiovasc Electrophysiol. 2007; 18:123-127. [PubMed: 16911576]

10. Deng GM, Verdrengh M, Liu ZQ, Tarkowski A. The major role of macrophages and their product tumor necrosis factor alpha in the induction of arthritis triggered by bacterial DNA containing CpG motifs. Arthritis Rheum. 2000; 43:2283-2289. [PubMed: 11037888]

11. Desmouliere A, Geinoz A, Gabbiani F, Gabbiani G. Transforming growth factor-beta 1 induces alpha-smooth muscle actin expression in granulation tissue myofibroblasts and in quiescent and growing cultured fibroblasts. J Cell Biol. 1993; 122:103-111. [PubMed: 8314838]

12. Dewald O, Ren G, Duerr GD, Zoerlein M, Klemm C, Gersch C, Tincey S, Michael LH, Entman ML, Frangogiannis NG. Of mice and dogs: species-specific differences in the inflammatory response following myocardial infarction. Am J Pathol. 2004; 164:665-677. [PubMed: 14742270]

13. Dubinett SM, Huang M, Dhanani S, Wang J, Beroiza T. Down-regulation of macrophage transforming growth factor-beta messenger RNA expression by IL-7. J Immunol. 1993; 151:66706680. [PubMed: 8258684]

14. El-Helou V, Proulx C, Gosselin H, Clement R, Mimee A, Villeneuve L, Calderone A. Dexamethasone treatment of post-MI rats attenuates sympathetic innervation of the infarct region. J Appl Physiol. 2007; 104:150-156. [PubMed: 17916672]

15. Fischer P, Hilfiker-Kleiner D. Survival pathways in hypertrophy and heart failure: the gp130STAT axis. Basic Res Cardiol. 2007; 102:393-411. [PubMed: 17918316]

16. Frangogiannis NG. The mechanistic basis of infarct healing. Antioxid Redox Signal. 2006; 8:1907-1939. [PubMed: 17034340]

17. Frangogiannis NG, Lindsey ML, Michael LH, Youker KA, Bressler RB, Mendoza LH, Spengler RN, Smith CW, Entman ML. Resident cardiac mast cells degranulate and release preformed TNFalpha, initiating the cytokine cascade in experimental canine myocardial ischemia/reperfusion. Circulation. 1998; 98:699-710. [PubMed: 9715863]

18. Frangogiannis NG, Youker KA, Rossen RD, Gwechenberger M, Lindsey MH, Mendoza LH, Michael LH, Ballantyne CM, Smith CW, Entman ML. Cytokines and the microcirculation in ischemia and reperfusion. J Mol Cell Cardiol. 1998; 30:2567-2576. [PubMed: 9990529]

19. Frantz S, Hu K, Adamek A, Wolf J, Sallam A, Maier SK, Lonning S, Ling H, Ertl G, Bauersachs J. Transforming growth factor beta inhibition increases mortality and left ventricular dilatation after myocardial infarction. Basic Res Cardiol. 2008; 103:485-492. [PubMed: 18651091]

20. Frucht DM, Fukao T, Bogdan C, Schindler H, O'Shea JJ, Koyasu S. IFN-gamma production by antigen-presenting cells: mechanisms emerge. Trends Immunol. 2001; 22:556-560. [PubMed: 11574279]

21. Gabbiani G. The cellular derivation and the life span of the myofibroblast. Pathol Res Pract. 1996; 192:708-711. [PubMed: 8880871]

22. Galeazzi F, Haapala EM, van Rooijen N, Vallance BA, Collins SM. Inflammation-induced impairment of enteric nerve function in nematode-infected mice is macrophage dependent. Am J Physiol Gastrointest Liver Physiol. 2000; 278:G259-G265. [PubMed: 10666050]

23. Gessani S, Belardelli F. IFN-gamma expression in macrophages and its possible biological significance. Cytokine Growth Factor Rev. 1998; 9:117-123. [PubMed: 9754706]

24. Grace SL, Fry R, Cheung A, Stewart DE. Cardiovascular disease. BMC Womens Health. 2004; 4(Suppl 1):S15. [PubMed: 15345078] 
25. Green SJ, Crawford RM, Hockmeyer JT, Meltzer MS, Nacy CA. Leishmania major amastigotes initiate the L-arginine-dependent killing mechanism in IFN-gamma-stimulated macrophages by induction of tumor necrosis factor-alpha. J Immunol. 1990; 145:4290-4297. [PubMed: 2124240]

26. Hasan W, Jama A, Donohue T, Wernli G, Onyszchuk G, Al-Hafez B, Bilgen M, Smith PG. Sympathetic hyper-innervation and inflammatory cell NGF synthesis following myocardial infarction in rats. Brain Res. 2006; 1124:142-154. [PubMed: 17084822]

27. Hasan W, Zhang R, Liu M, Warn JD, Smith PG. Coordinate expression of NGF and alpha-smooth muscle actin mRNA and protein in cutaneous wound tissue of developing and adult rats. Cell Tissue Res. 2000; 300:97-109. [PubMed: 10805079]

28. Ieda M, Kanazawa H, Kimura K, Hattori F, Ieda Y, Taniguchi M, Lee JK, Matsumura K, Tomita Y, Miyoshi S, Shimoda K, Makino S, Sano M, Kodama I, Ogawa S, Fukuda K. Sema3a maintains normal heart rhythm through sympathetic innervation patterning. Nat Med. 2007; 13:604-612. [PubMed: 17417650]

29. Irwin MW, Mak S, Mann DL, Qu R, Penninger JM, Yan A, Dawood F, Wen WH, Shou Z, Liu P. Tissue expression and immunolocalization of tumor necrosis factor-alpha in postinfarction dysfunctional myocardium. Circulation. 1999; 99:1492-1498. [PubMed: 10086975]

30. Kannel WB, Hjortland MC, McNamara PM, Gordon T. Menopause and risk of cardiovascular disease: the Framingham study. Ann Intern Med. 1976; 85:447-452. [PubMed: 970770]

31. Kim LR, Whelpdale K, Zurowski M, Pomeranz B. Sympathetic denervation impairs epidermal healing in cutaneous wounds. Wound Repair Regen. 1998; 6:194-201. [PubMed: 9776863]

32. Lee TM, Lin MS, Chang NC. Effect of pravastatin on sympathetic reinnervation in postinfarcted rats. Am J Physiol Heart Circ Physiol. 2007; 293:H3617-H3626. [PubMed: 17890424]

33. Lee TM, Lin MS, Chang NC. Physiological concentration of 17beta-estradiol on sympathetic reinnervation in ovariectomized infarcted rats. Endocrinology. 2007; 120:5-1213.

34. Levi-Montalcini R. The nerve growth factor 35 years later. Science. 1987; 237:1154-1162. [PubMed: 3306916]

35. Li W, Knowlton D, Van Winkle DM, Habecker BA. Infarction alters both the distribution and noradrenergic properties of cardiac sympathetic neurons. Am J Physiol Heart Circ Physiol. 2004; 286:H2229-H2236. [PubMed: 14726300]

36. Lie JT, Pairolero PC, Holley KE, Titus JL. Macroscopic enzyme-mapping verification of large, homogeneous, experimental myocardial infarcts of predictable size and location in dogs. J Thorac Cardiovasc Surg. 1975; 69:599-605. [PubMed: 1117748]

37. Lindholm D, Castren E, Berzaghi M, Blochl A, Thoenen H. Activity-dependent and hormonal regulation of neurotrophin mRNA levels in the brain-implications for neuronal plasticity. $\mathbf{J}$ Neurobiol. 1994; 25:1362-1372. [PubMed: 7852991]

38. McClellan SA, Huang X, Barrett RP, van Rooijen N, Hazlett LD. Macrophages restrict Pseudomonas aeruginosa growth, regulate polymorphonuclear neutrophil influx, and balance proand anti-inflammatory cytokines in BALB/c mice. J Immunol. 2003; 170:5219-5227. [PubMed: 12734370]

39. Micera A, Puxeddu I, Aloe L, Levi-Schaffer F. New insights on the involvement of nerve growth factor in allergic inflammation and fibrosis. Cytokine Growth Factor Rev. 2003; 14:369-374. [PubMed: 12948520]

40. Micklem K, Rigney E, Cordell J, Simmons D, Stross P, Turley H, Seed B, Mason D. A human macrophage-associated antigen (CD68) detected by six different monoclonal antibodies. $\mathrm{Br} \mathrm{J}$ Haematol. 1989; 73:6-11. [PubMed: 2803980]

41. Miura T, Miki T. Limitation of myocardial infarct size in the clinical setting: current status and challenges in translating animal experiments into clinical therapy. Basic Res Cardiol. 2008; 103:501-513. [PubMed: 18716709]

42. Mizutani H, May LT, Sehgal PB, Kupper TS. Synergistic interactions of IL-1 and IL-6 in T cell activation. Mitogen but not antigen receptor-induced proliferation of a cloned T helper cell line is enhanced by exogenous IL-6. J Immunol. 1989; 143:896-901. [PubMed: 2526177]

43. Moalem G, Gdalyahu A, Shani Y, Otten U, Lazarovici P, Cohen IR, Schwartz M. Production of neurotrophins by activated T cells: implications for neuroprotective autoimmunity. J Autoimmun. 2000; 15:331-345. [PubMed: 11040074] 
44. Munder M, Mallo M, Eichmann K, Modolell M. Murine macrophages secrete interferon gamma upon combined stimulation with interleukin (IL)-12 and IL-18: a novel pathway of autocrine macrophage activation. J Exp Med. 1998; 187:2103-2108. [PubMed: 9625771]

45. Myerburg, RJ.; Castellanos, A. Cardiac arrest and sudden cardiac death. WB Saunders; Philadelphia: 1992.

46. Myerburg RJ, Kessler KM, Castellanos A. Sudden cardiac death. Structure, function, and timedependence of risk. Circulation. 1992; 85:I2-I10. [PubMed: 1728501]

47. Onai Y, Suzuki J, Kakuta T, Maejima Y, Haraguchi G, Fukasawa H, Muto S, Itai A, Isobe M. Inhibition of IkappaB phosphorylation in cardiomyocytes attenuates myocardial ischemia/ reperfusion injury. Cardiovasc Res. 2004; 63:51-59. [PubMed: 15194461]

48. Popovich PG, Guan Z, Wei P, Huitinga I, van Rooijen N, Stokes BT. Depletion of hematogenous macrophages promotes partial hindlimb recovery and neuroanatomical repair after experimental spinal cord injury. Exp Neurol. 1999; 158:351-365. [PubMed: 10415142]

49. Salkowski CA, Neta R, Wynn TA, Strassmann G, van Rooijen N, Vogel SN. Effect of liposomemediated macrophage depletion on LPS-induced cytokine gene expression and radioprotection. $\mathbf{J}$ Immunol. 1995; 155:3168-3179. [PubMed: 7673730]

50. Schmitt-Graff A, Desmouliere A, Gabbiani G. Heterogeneity of myofibroblast phenotypic features: an example of fibroblastic cell plasticity. Virchows Arch. 1994; 425:3-24. [PubMed: 7921410]

51. Selye H, Bajusz E, Grasso S, Mendell P. Simple techniques for the surgical occlusion of coronary vessels in the rat. Angiology. 1960; 11:398-407. [PubMed: 13749954]

52. Shelton DL, Reichardt LF. Expression of the beta-nerve growth factor gene correlates with the density of sympathetic innervation in effector organs. Proc Natl Acad Sci USA. 1984; 81:79517955. [PubMed: 6595669]

53. Skalli O, Ropraz P, Trzeciak A, Benzonana G, Gillessen D, Gabbiani G. A monoclonal antibody against alpha-smooth muscle actin: a new probe for smooth muscle differentiation. J Cell Biol. 1986; 103:2787-2796. [PubMed: 3539945]

54. Smith PG, Liu M. Impaired cutaneous wound healing after sensory denervation in developing rats: effects on cell proliferation and apoptosis. Cell Tissue Res. 2002; 307:281-291. [PubMed: 11904764]

55. Solomon SD, Zelenkofske S, McMurray JJ, Finn PV, Velazquez E, Ertl G, Harsanyi A, Rouleau JL, Maggioni A, Kober L, White H, Van de Werf F, Pieper K, Califf RM, Pfeffer MA. Sudden death in patients with myocardial infarction and left ventricular dysfunction, heart failure, or both. N Engl J Med. 2005; 352:2581-2588. [PubMed: 15972864]

56. Souza BR, Cardoso JF, Amadeu TP, Desmouliere A, Costa AM. Sympathetic denervation accelerates wound contraction but delays reepithelialization in rats. Wound Repair Regen. 2005; 13:498-505. [PubMed: 16176458]

57. Spiekstra SW, Breetveld M, Rustemeyer T, Scheper RJ, Gibbs S. Wound-healing factors secreted by epidermal keratinocytes and dermal fibroblasts in skin substitutes. Wound Repair Regen. 2007; 15:708-717. [PubMed: 17971017]

58. Summan M, Warren GL, Mercer RR, Chapman R, Hulderman T, Van Rooijen N, Simeonova PP. Macrophages and skeletal muscle regeneration: a clodronate-containing liposome depletion study. Am J Physiol Regul Integr Comp Physiol. 2006; 290:R1488-R1495. [PubMed: 16424086]

59. Torres PF, Slegers TP, Peek R, van Rooijen N, van der Gaag R, Kijlstra A, de Vos AF. Changes in cytokine mRNA levels in experimental corneal allografts after local clodronate-liposome treatment. Invest Ophthalmol Vis Sci. 1999; 40:3194-3201. [PubMed: 10586942]

60. van Amerongen MJ, Harmsen MC, van Rooijen N, Petersen AH, van Luyn MJ. Macrophage depletion impairs wound healing and increases left ventricular remodeling after myocardial injury in mice. Am J Pathol. 2007; 170:818-829. [PubMed: 17322368]

61. Van Rooijen N, Sanders A. Liposome mediated depletion of macrophages: mechanism of action, preparation of liposomes and applications. J Immunol Methods. 1994; 174:83-93. [PubMed: 8083541]

62. van Rooijen N, Sanders A, van den Berg TK. Apoptosis of macrophages induced by liposomemediated intracellular delivery of clodronate and propamidine. J Immunol Methods. 1996; 193:93-99. [PubMed: 8690935] 
63. Vracko R, Thorning D, Frederickson RG. Nerve fibers in human myocardial scars. Hum Pathol. 1991; 22:138-146. [PubMed: 1705914]

64. Westermann D, Van Linthout S, Dhayat S, Dhayat N, Schmidt A, Noutsias M, Song XY, Spillmann F, Riad A, Schultheiss HP, Tschope C. Tumor necrosis factor-alpha antagonism protects from myocardial inflammation and fibrosis in experimental diabetic cardiomyopathy. Basic Res Cardiol. 2007; 102:500-507. [PubMed: 17909696]

65. Zhou S, Chen LS, Miyauchi Y, Miyauchi M, Kar S, Kangavari S, Fishbein MC, Sharifi B, Chen PS. Mechanisms of cardiac nerve sprouting after myocardial infarction in dogs. Circ Res. 2004; 95:76-83. [PubMed: 15166093]

66. Zoubina EV, Fan Q, Smith PG. Variations in uterine innervation during the estrous cycle in rat. J Comp Neurol. 1998; 397:561-571. [PubMed: 9699916]

67. Zoubina EV, Mize AL, Alper RH, Smith PG. Acute and chronic estrogen supplementation decreases uterine sympathetic innervation in ovariectomized adult virgin rats. Histol Histopathol. 2001; 16:989-996. [PubMed: 11642748] 


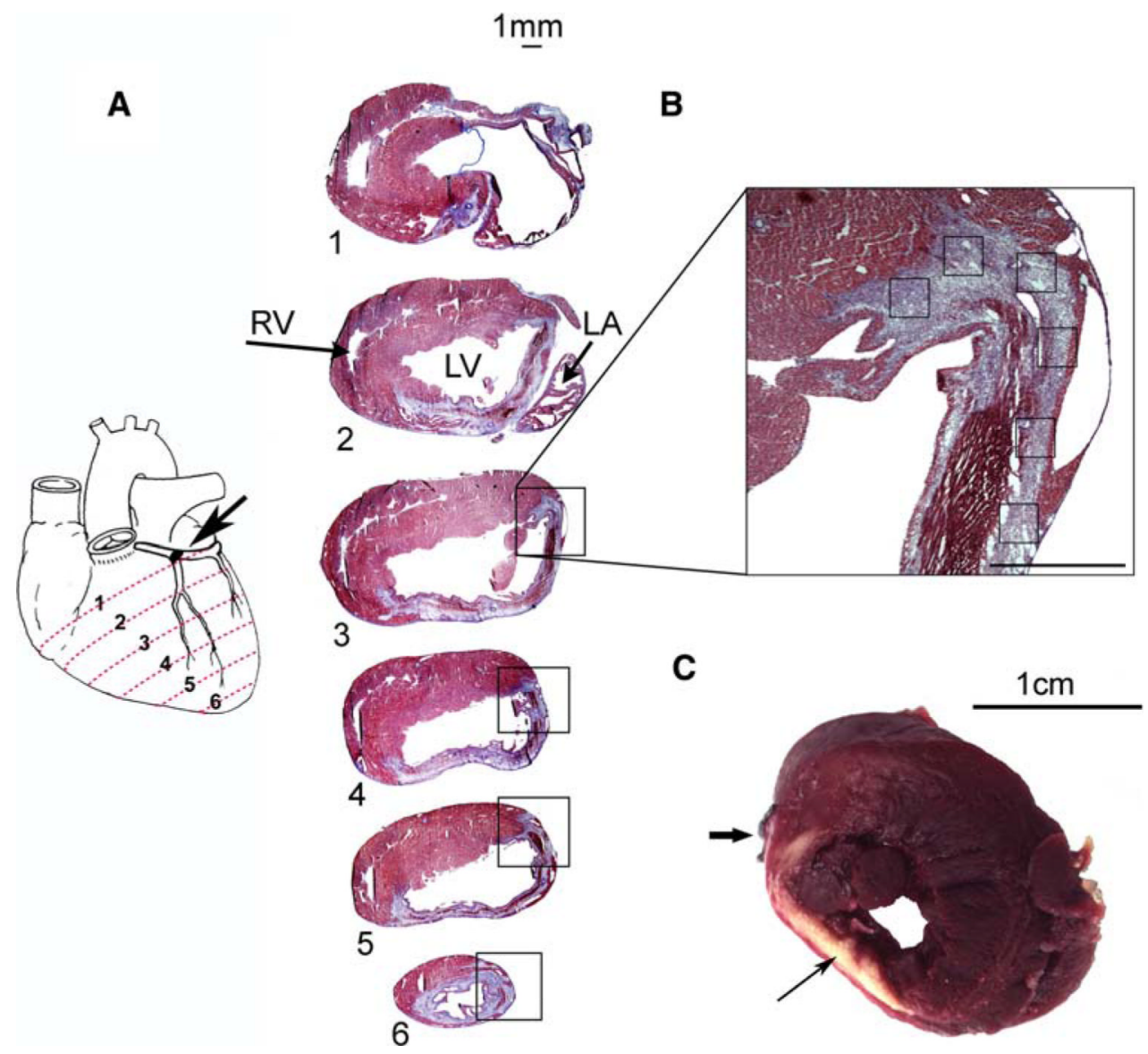

Fig. 1.

Infarct assessment. a Six sections taken at $\sim 1.7 \mathrm{~mm}$ intervals through the entire ventricle stained with Masson's trichrome. Collagen is lightly stained and cardiomyocytes are darker. Arrow in the schematic diagram shows where the left coronary artery was ligated, and dotted lines show the levels from which each of the representative sections was taken. $R V$ right ventricle, $L V$ left ventricle, $L A$ left atrium. Boxes show the regions sampled for the analysis sympathetic innervation and inflammatory cells. b Higher magnification of area shown in section 3. Boxes in b show fields within the left lateral posterior aspect of the infarct sampled for quantification. Scale $1 \mathrm{~mm}$. c Approximately $2 \mathrm{~mm}$ section through a CAL heart stained with TTC. Large arrow shows the suture. Thin arrow shows the infarct, which fails to stain with TTC 

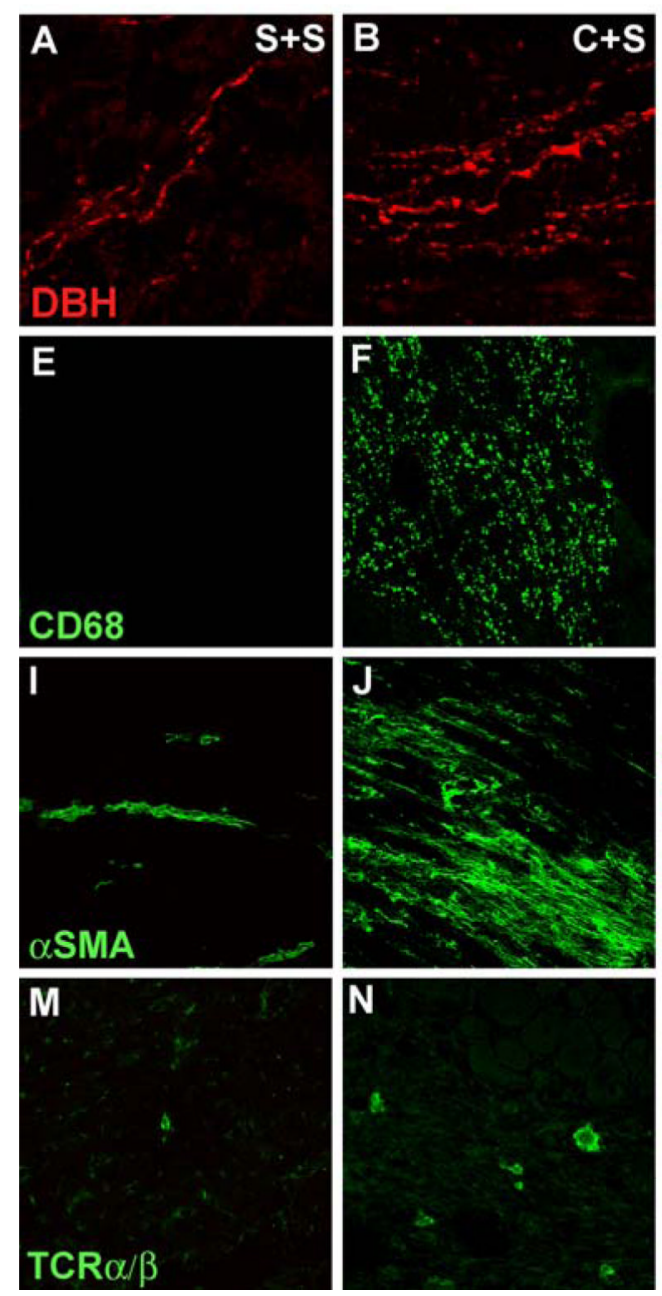

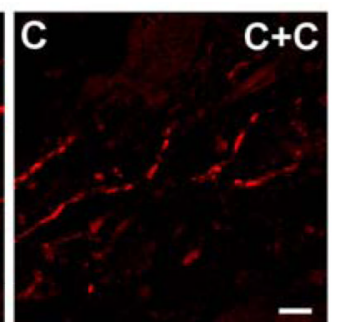

G.
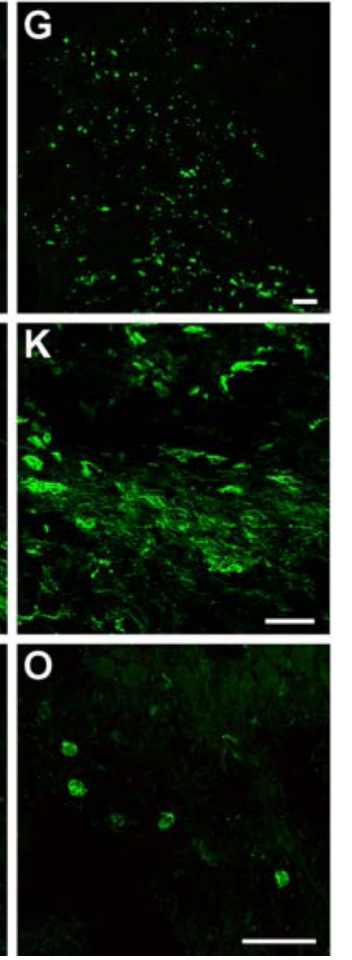

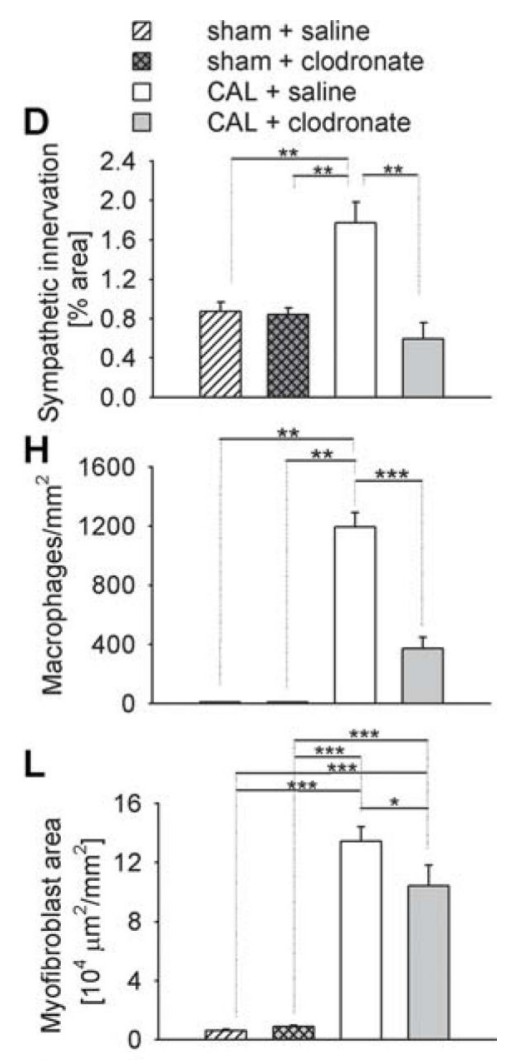

$\mathbf{P}$

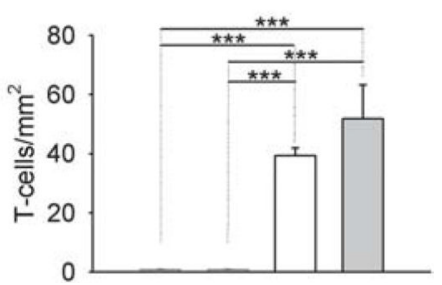

Fig. 2.

Innervation and inflammatory cell composition of uninjured and injured hearts.

Immunostaining of ventricular tissue sections for dopamine $\beta$-hydroxylase (DBH) as a sympathetic nerve marker $(\mathbf{a}-\mathbf{c})$, CD68 as a macrophage marker $(\mathbf{e}-\mathbf{g})$, $\mathbf{a}$-Smooth muscle actin (aSMA) as a myofibroblast marker (i-k), and TCRa/ $\beta$ as a T cell marker $(\mathbf{m}-\mathbf{o})$.

Sections were obtained from rats receiving sham ligation and saline injections $(\mathrm{S}+\mathrm{S}, \mathbf{a}, \mathbf{e}, \mathbf{i}$, $\mathbf{m})$, coronary artery ligation and saline injections $(C+S, \mathbf{b}, \mathbf{f}, \mathbf{j}, \mathbf{n})$, or coronary artery ligations plus clodronate liposomes $(\mathrm{C}+\mathrm{C}, \mathbf{c}, \mathbf{g}, \mathbf{k}, \mathbf{o})$. Scale bar $10 \mu \mathrm{m}$ in $\mathbf{c}$ and $50 \mu \mathrm{m}$ in $\mathbf{g}$, $\mathbf{k}$, and $\mathbf{o . d}$ Quantitative analysis of sympathetic innervation density as determined by the percentage of section sample area occupied by DBH-ir nerves. h Quantitative analysis of tissue macrophages expressed as the number of CD68-ir cells per $\mathrm{mm}^{2}$. 1 Quantitative analysis of tissue myofibroblasts as determined by the section sample area occupied by $a-$ SMA-ir. p Quantitation of tissue T cells as determined by the number of TcRa/ $\beta$ cells per $\mathrm{mm}^{2}$. $* P<0.05, * * P<0.01, * * * P<0.001$ 

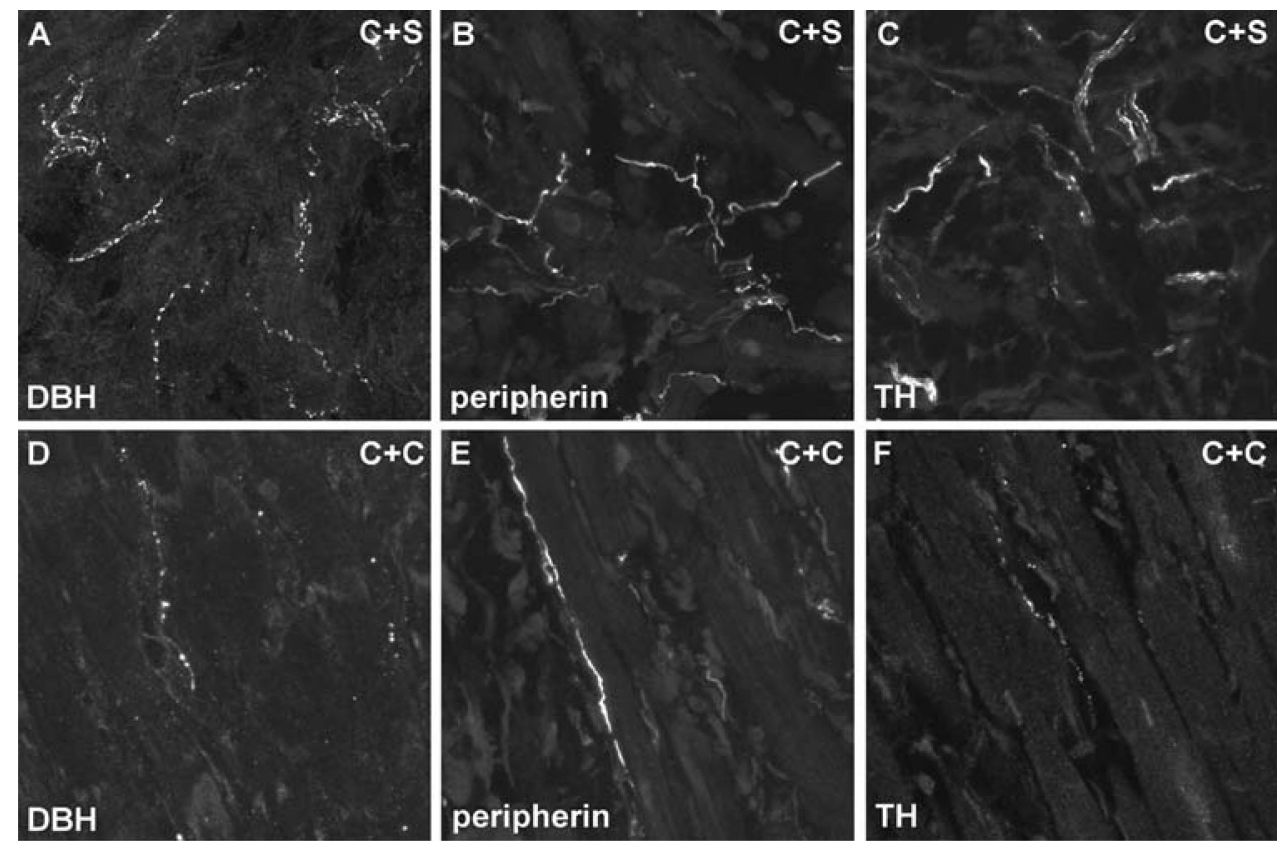

Fig. 3.

Changes in sympathetic innervation after clodronate liposome treatment are reflected by multiple markers. Adjacent sections from hearts receiving coronary artery ligation plus saline $(\mathrm{C}+\mathrm{S})$ or ligation plus clodronate liposomes $(\mathrm{C}+\mathrm{C})$ were immunostained for $\mathrm{DBH}$, which characterizes noradrenergic neurons $(\mathbf{a}, \mathbf{d})$, the intermediate filament protein peripherin which stains intact unmyelinated axons $(\mathbf{b}, \mathbf{e})$, and tyrosine hydroxylase that is a marker for catecholaminergic axons $(\mathbf{c}, \mathbf{f})$. Levels of innervation density were comparable under different treatments with all markers. Scale bar $10 \mu \mathrm{m}$ 

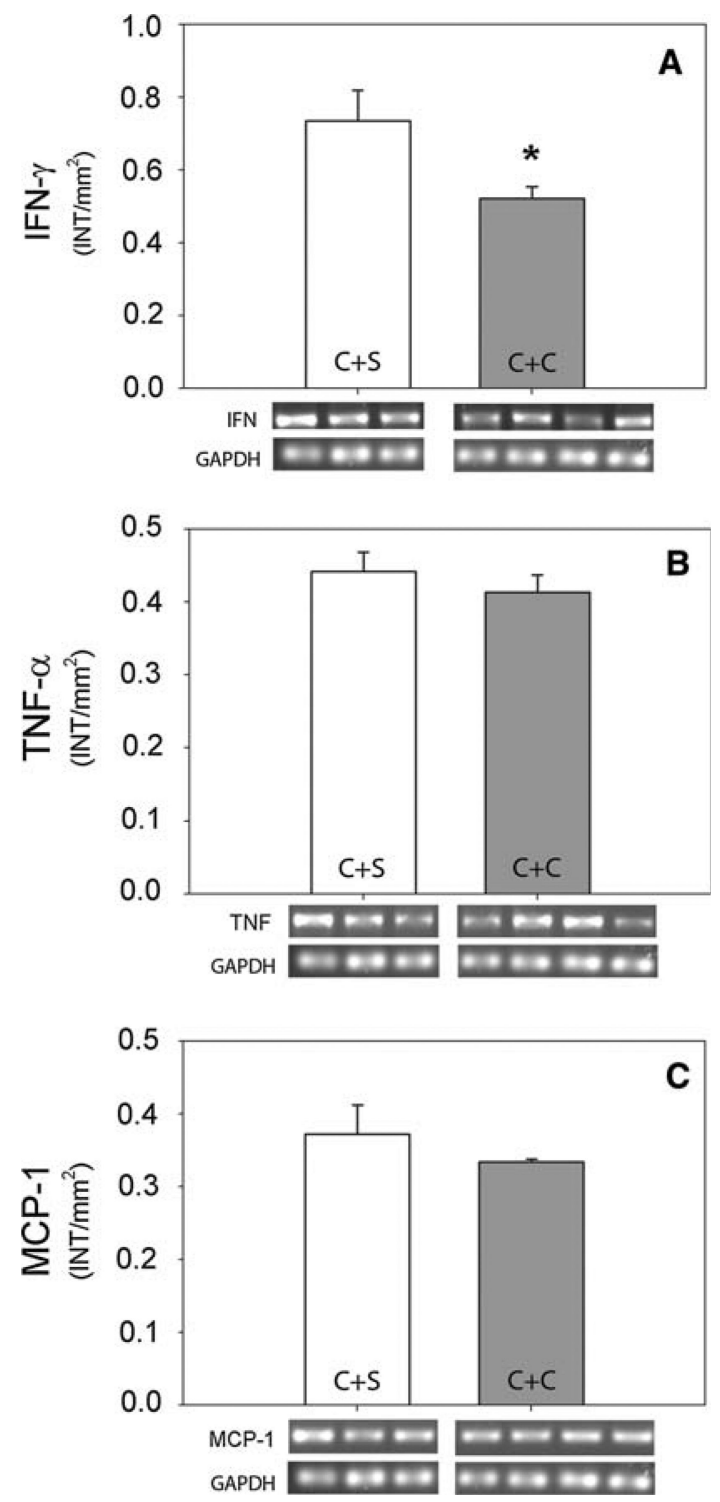

Fig. 4.

Effect of clodronate liposomes on IFN- $\gamma$, TNF- $a$, and MCP-1 mRNA in the infarction border region. Infarct tissue was assessed by RT-PCR for Interferon- $\gamma$ (IFN), tumor necrosis factor (TNF-a), and macrophage chemotactic protein-1 in infarct tissue 7 days after CAL in rats receiving saline-containing liposomes $(\mathrm{C}+\mathrm{S})$ or clodronate-containing liposomes $(\mathrm{C}+$ C). RT-PCR product was analyzed densitometrically (intensity $/ \mathrm{mm}^{2}$ ) and normalized to GAPDH. $* P<0.05$ 


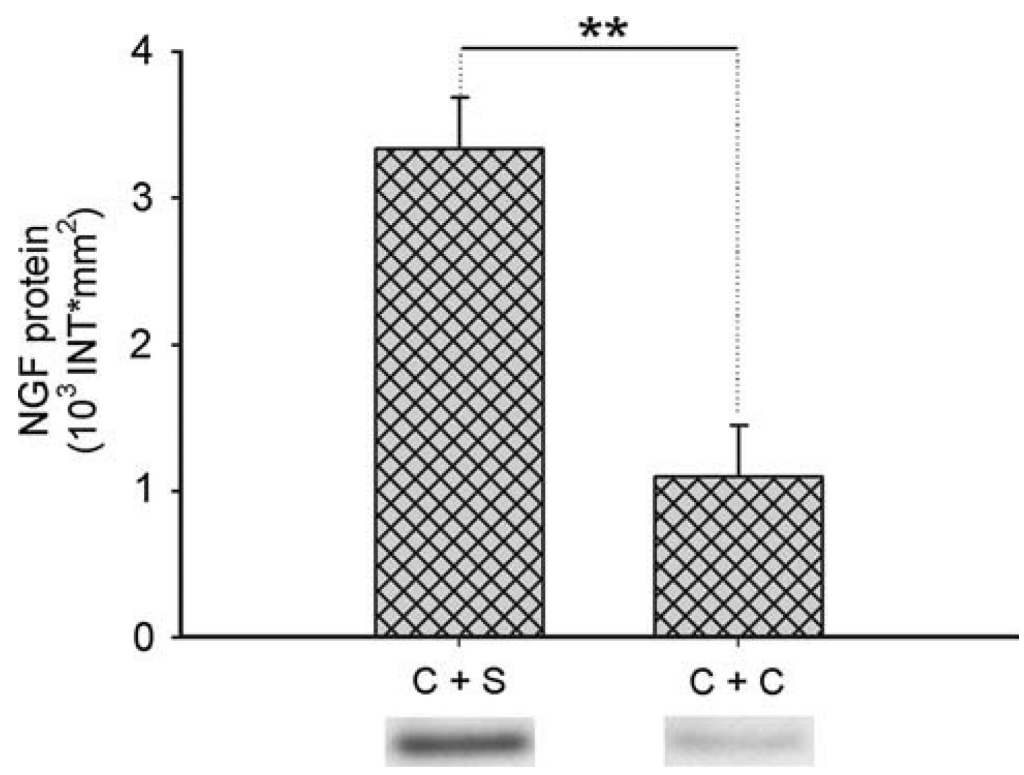

Fig. 5.

Effect of clodronate liposomes on NGF in the infarction border region. Tissue was assessed by western blot for NGF 7 days after CAL in rats receiving saline-containing liposomes $(\mathrm{C}$ $+\mathrm{S})$ or clodronate-containing liposomes $(\mathrm{C}+\mathrm{C})$. Product was analyzed densitometrically and normalized to total protein. $* * P<0.01$ 

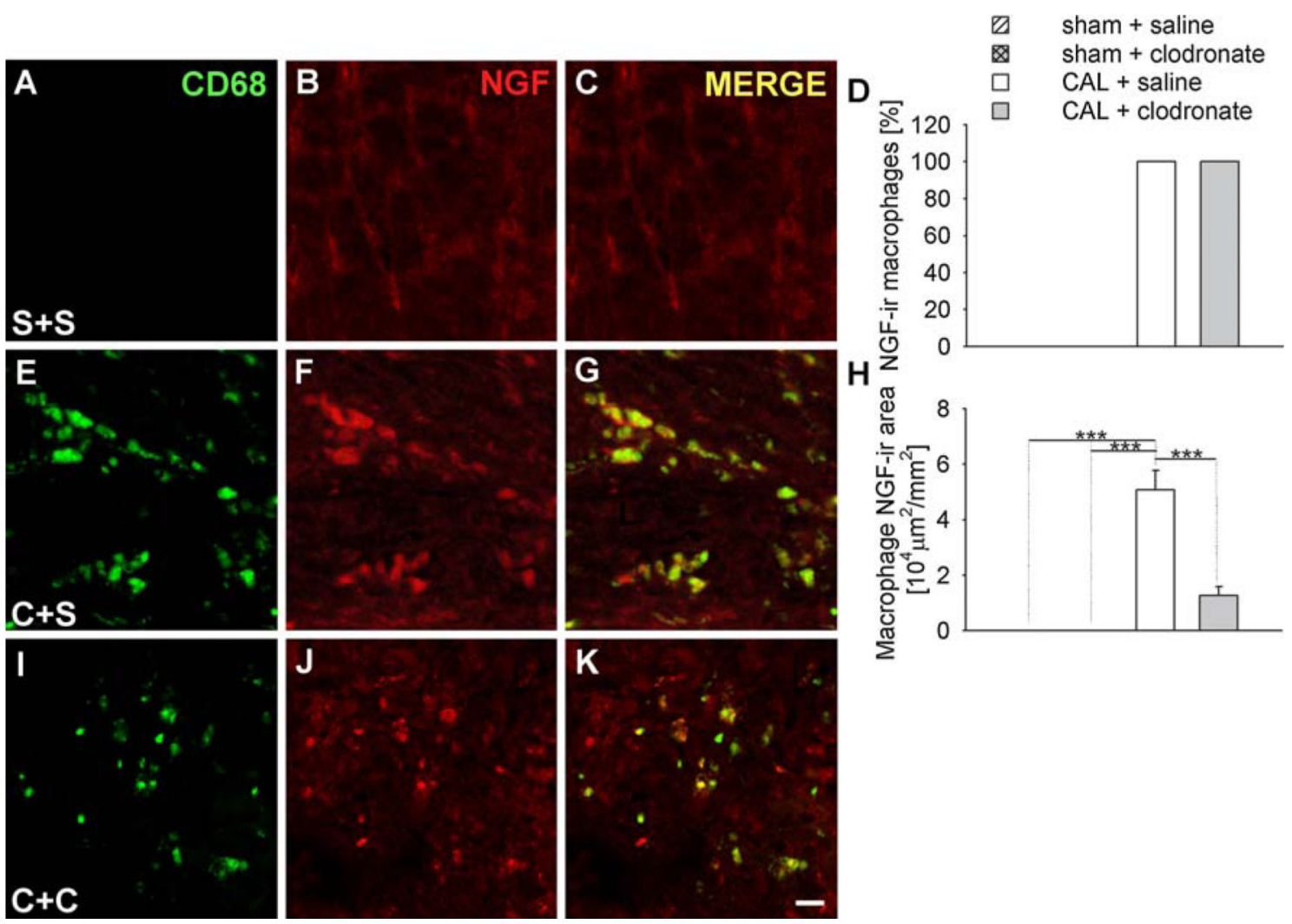

Fig. 6.

Effect of clodronate liposomes on macrophage NGF expression. Immunostaining for CD68 as a macrophage marker (a, e, i), and co-stained for $\operatorname{NGF}(\mathbf{b}, \mathbf{f}, \mathbf{j})$, merged images $(\mathbf{c}, \mathbf{g}, \mathbf{k})$. Sections were obtained from rats receiving sham ligation and saline injections $(S+S, \mathbf{a}, \mathbf{b}, \mathbf{c})$, coronary artery ligation and saline injection $(\mathrm{C}+\mathrm{S}, \mathbf{e}, \mathbf{f}, \mathbf{g})$, or coronary artery ligation plus clodronate liposomes $(\mathrm{C}+\mathrm{C}, \mathbf{i}, \mathbf{j}, \mathbf{k})$. Scale bar $10 \mu \mathrm{m}$. Quantitative analysis of the percentage (d) and the area (h) of macrophages expressing NGF-ir as determined by the area of CD68ir coexpressing NGF-ir. $* * * P<0.001$ 

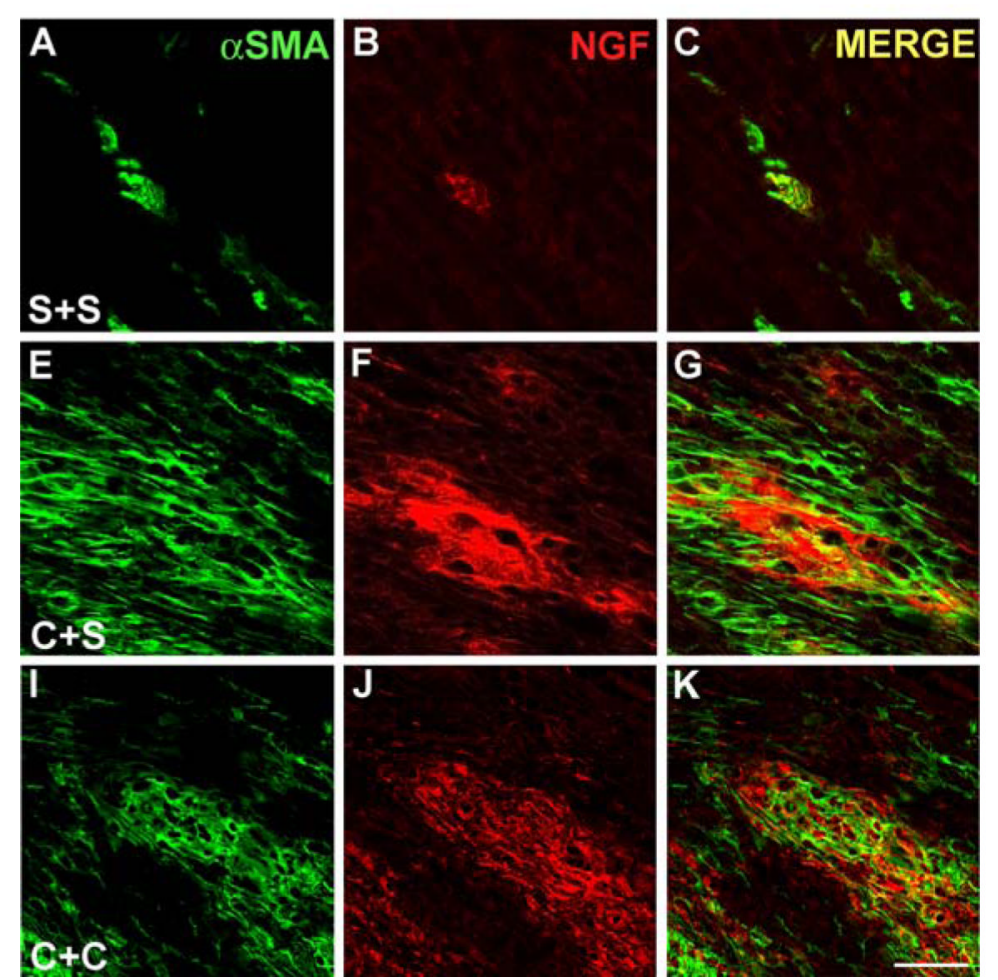

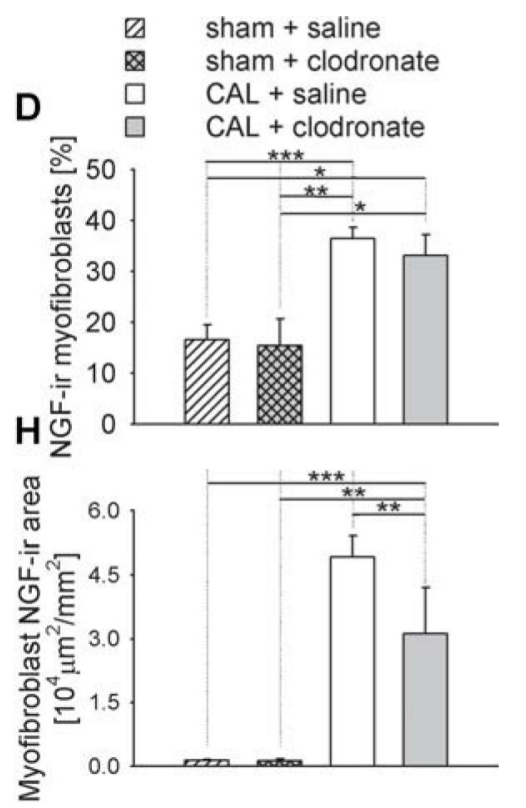

Fig. 7.

Effect of clodronate liposomes on NGF expression by myofibroblasts. Immunostaining for a-SMA as a myofibroblast marker (a, e, i), and co-stained for NGF $(\mathbf{b}, \mathbf{f}, \mathbf{j})$, and merged images $(\mathbf{c}, \mathbf{g}, \mathbf{k})$. Sections were obtained from rats receiving sham ligation and saline injections $(\mathrm{S}+\mathrm{S}, \mathbf{a}, \mathbf{b}, \mathbf{c})$, coronary artery ligation and saline injection $(\mathrm{C}+\mathrm{S}, \mathbf{e}, \mathbf{f}, \mathbf{g})$, or coronary artery ligation plus clodronate liposomes $(\mathrm{C}+\mathrm{C}, \mathbf{i}, \mathbf{j}, \mathbf{k})$. Scale bar $50 \mu \mathrm{m}$. Quantitative analysis of the percentage (d) and the area (h) of myofibroblasts expressing NGF-ir as determined by the area of a-SMA-ir coexpressing NGF-ir. $* P<0.05$, ** $P<$ $0.01, * * * P<0.001$ 

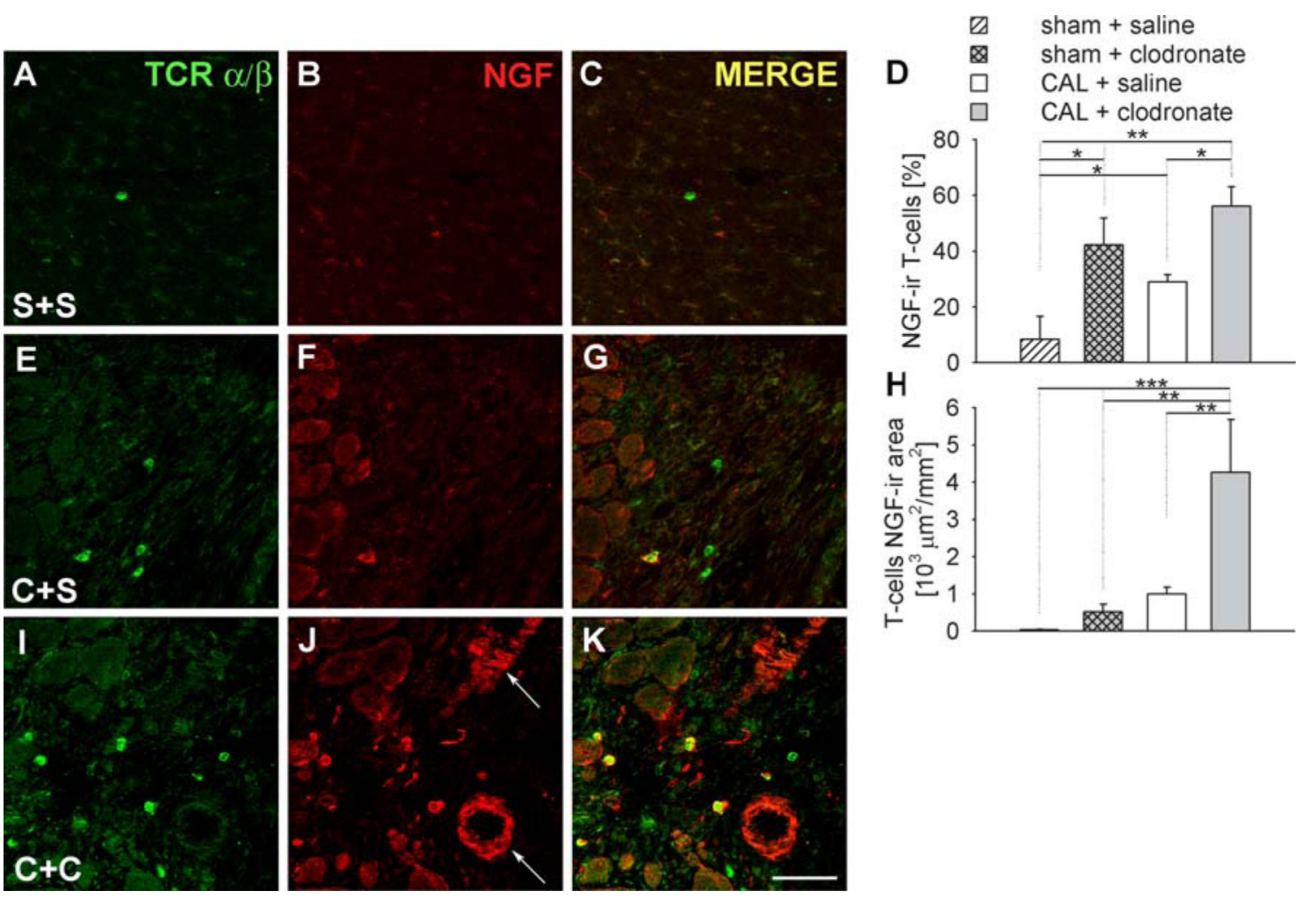

Fig. 8.

Effect of clodronate liposomes on NGF expression by T cells. Immunostaining for TCR $\alpha / \beta$ as a T cell marker (a, e, i), and co-stained for NGF (b, f, j), merged images $(\mathbf{c}, \mathbf{g}, \mathbf{k})$.

Sections were obtained from rats receiving sham ligation and saline injections $(\mathrm{S}+\mathrm{S}, \mathbf{a}-\mathbf{c})$, coronary artery ligation and saline injection $(\mathrm{C}+\mathrm{S}, \mathbf{e}-\mathbf{g})$, or coronary artery ligation plus clodronate liposomes $(\mathrm{C}+\mathrm{C}, \mathbf{i}-\mathbf{k})$. Arrows shows blood vessels expressing NGF. Scale bar $50 \mu \mathrm{m}$. Quantitative analysis of the percentage (d) and the area (h) of T cells expressing NGF-ir as determined by the area of TCR a/ $\beta$-ir coexpressing NGF-ir. $* P<0.05$, ** $P<$ $0.01, * * * P<0.001$ 